\title{
Protein-energy malnutrition in pregnant rats improves the adaptation of the endocrine pancreas in malnourished offspring and induces insulin resistance after rehabilitation
}

\author{
BY JEAN-MARC DOLLET*, BERNARD BECK \\ AND JEAN-PIERRE MAX \\ Unité de Recherches sur les Mécanismes de Régulation du Comportement Alimentaire, \\ INSERM U.308, 38 rue Lionnois, 54000 Nancy, France \\ AND GÉRARD DEBRY \\ Département de Nutrition et des Maladies Métaboliques, Université de Nancy I, \\ 54000 Nancy, France
}

(Received 17 March 1987 - Accepted 17 July 1987)

1. In developing countries, malnutrition begins during pregnancy and lactation. Glucose intolerance is a problem of importance during protein-energy malnutrition (PEM). We therefore studied glucose homeostasis in rats weaned from undernourished mothers.

2. On weaning, 156 male Wistar rats, born from deprived mothers ( $75 \mathrm{~g}$ casein $/ \mathrm{kg}$ diet), were fed $a d l i b$ on either a balanced diet ( $180 \mathrm{~g}$ casein $/ \mathrm{kg}$; group DR), or a protein-deficient diet ( $50 \mathrm{~g}$ casein $/ \mathrm{kg}$; group DD). At seven time intervals (weeks $0,1,3,5,8,16$ and 23) twelve rats were weighed, fasted overnight and then decapitated. Blood glucose, plasma insulin (IRI) and glucagon (IRG) levels and pancreatic insulin and glucagon contents were determined.

3. In DR and DD rats blood glucose, which was normal at weaning, dropped in the 1st week and then increased slowly. DR rats were hyperglycaemic from week 16 . IRI continually increased during the experiment from nearnormal values to hyperinsulinic levels in DR rats; in group DD, it remained stable until week 8 before increasing. IRG, which was very low at weaning, increased to normal levels in the 1st week in group DR; in group DD, it fell slightly during the study. Pancreatic hormone contents were much higher than after normal pregnancy and lactation.

4. We compared these results with those of a previous study with rats born from normal mothers: at weaning in the second experiment the rats were already well adapted to malnutrition. The plasma ratio IRI:IRG in DD rats showed two phases of adaptation: weeks $0-5$ when glucose homeostasis did not change and weeks 5-23 when it became increasingly normal. At the end of the experiment DR rats still had a lower body-weight than normal rats but were insulin-resistant.

Protein-energy malnutrition (PEM) leads to glucose intolerance in children (James \& Coore, 1970; Milner, 1971) and in rats (Weinkove et al. 1976). In a previous study with rats born from normal mothers (Dollet et al. 1985), we showed that there were three phases of adaptation of the endocrine pancreas in rats fed on a low-protein diet after weaning.

In developing countries, mothers are often undernourished during both pregnancy and lactation (Coward et al. 1984), and the body-weights of their children are therefore low at birth and at weaning (Tafari et al. 1980). The cellularity of the pancreas is also modified in these children (Gabr, 1981; Rengers \& Zeman, 1983). Maternal lactation is also very important for body and pancreatic growth in rats (Crnic \& Chase, 1978; Beck et al. 1982). When undernourished rats born from normal and undernourished mothers were compared, the postweaning carbohydrate status was found to be worse in the latter rats (Heard \& Stewart, 1971). In order to improve our understanding of pancreatic adaptation in children from developing countries and changes in glucose homeostasis after rehabilitation, we used, as a model, rats born from mothers undernourished during both pregnancy and

* Present address: Service d'Hépatogastroentérologie, CHU de Brabois, 54500 Vandoeuvre les Nancy, France. 
Table 1. Composition of the control and protein-deficient diets $(\mathrm{g} / \mathrm{kg})$

\begin{tabular}{lcc}
\hline \hline Ingredient & Control & Protein-deficient \\
\hline Casein & 180 & 50 \\
Maize starch & 670 & 800 \\
Peanut oil & 80 & 80 \\
Salt mixture* & 40 & 40 \\
Vitamins* & 10 & 10 \\
Cellulose & 20 & 20 \\
Methionine & - & 2 \\
\hline
\end{tabular}

* Detailed composition given by Dollet et al. (1985).

lactation, and then either rehabilitated or submitted to mild PEM after weaning. We compared our results with those obtained in malnourished rats born from normal mothers (Dollet et al. 1985).

\section{MATERIAL AND METHODS \\ Animals and protocol}

Because this second study was carried out exactly 1 year after the first (Dollet et al. 1985), identical circannual fluctuations occurred in the two studies allowing us to compare the results.

From a total of 461 male Wistar rats, born in our laboratory from deprived mothers, we selected 156 animals of uniform body-weight at weaning (day 24). The deprived mothers were fed on a $75 \mathrm{~g}$ casein $/ \mathrm{kg}$ diet (previously described in Beck et al. 1983) from $15 \mathrm{~d}$ before mating until the end of the suckling period. Twelve rats were decapitated at weaning (week 0 ). The remaining rats were randomly distributed into two identical groups of seventy-two animals each: a group fed on $180 \mathrm{~g}$ casein $/ \mathrm{kg}$ diet (group DR; deprived before weaning and rehabilitated after weaning) and a group fed on a $50 \mathrm{~g}$ casein $/ \mathrm{kg}$ diet (group DD; deprived before weaning and deprived after weaning). The composition of these two diets is given in Table 1: they are the same as those used in the first study and were isoenergetic since maize starch replaced casein in the protein-deficient diet. Both diets were prepared in the laboratory and stored at $5^{\circ}$. Food and tap water were given ad lib. Food intake was measured daily in the same twelve rats of both groups throughout the study. The animals were housed in individual wire cages in an air-conditioned room with an automatic $12 \mathrm{~h}$ light $-12 \mathrm{~h}$ dark cycle, lights on at 07.00 hours.

\section{Sampling and assays}

Apart from the twelve rats killed at weaning (week 0), twelve rats of both groups were killed after $1,3,5,8,16$ and 23 weeks. The animals were weighed on the day before death. After a $16 \mathrm{~h}$ fasting period, the animals were decapitated and the arteriovenous blood was collected in a test-tube containing EDTA (Prolabo, Paris; $1 \mathrm{mg} / \mathrm{ml}$ ) and aprotinin (Iniprol ${ }^{\mathrm{R}}$, Choay, Paris; $4000 \mathrm{IU} / \mathrm{ml}$ ). At weeks 0 and 1 in DR rats and from week 0 to week 8 in DD rats, the plasma of two or three rats per group was pooled to obtain a sufficient quantity for all assays. Plasma was divided into portions and stored at $-20^{\circ}$ until blood glucose, immunoreactive insulin (IRI) and immunoreactive glucagon (IRG) were assayed. Immediately after death, the whole pancreases of six randomly selected rats of each group were carefully dissected, weighed and rapidly frozen in liquid nitrogen in a test-tube containing $200000 \mathrm{IU}$ aprotinin $/ \mathrm{ml}$. The pancreases were stored at $-20^{\circ}$ until insulin and glucagon were extracted. 


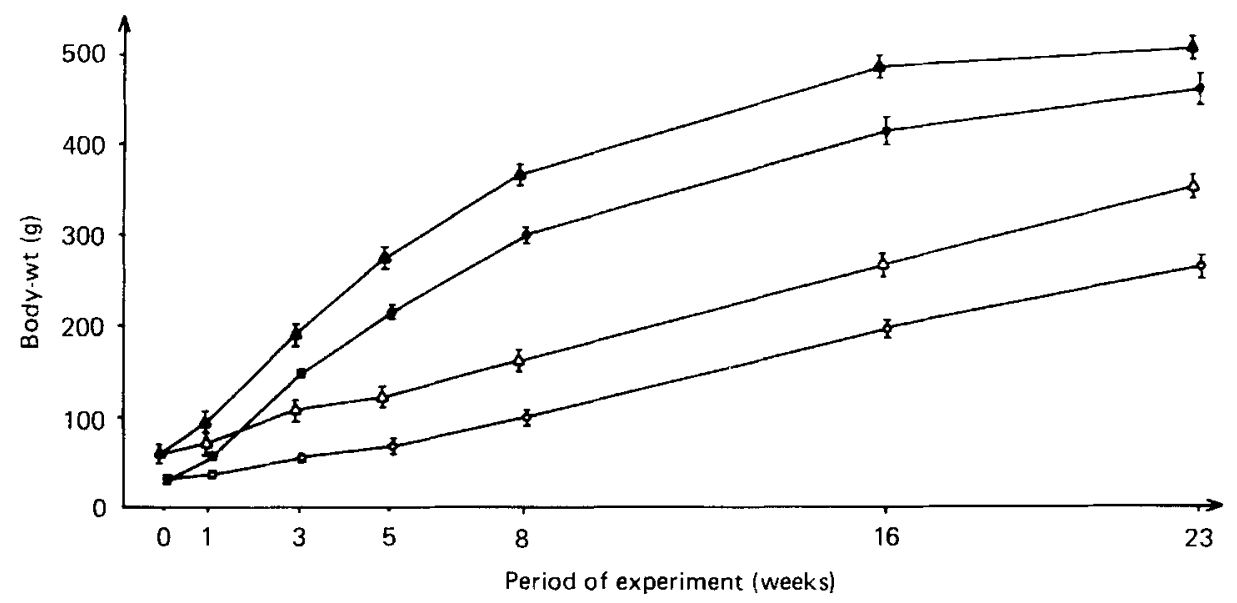

Fig. 1. Mean body-weight of control and experimental rats over a period of 23 weeks after weaning: ( -0$)$, rats deprived before weaning, rehabilitated after weaning; $(\mathrm{O}-\mathrm{O})$, rats deprived both before and after weaning; $(\boldsymbol{\Lambda}-\mathbf{\Delta})$, control rats born from normal mothers; $(\Delta-\triangle \Delta)$, proteindeficient rats born from normal mothers. Points are mean values, with 1 SEM represented by vertical bars. (Figure reproduced with permission of Nutrition Research.)

Extraction and assay methods were the same as in the first study and have been described previously (Dollet et al. 1985).

\section{Statistical methods}

Results are expressed as means with their standard errors. They were compared using Student's $t$ test (with Yates's modification). A probability of $P<0.05$ was considered significant.

\section{RESULTS}

Mean body-weight and food intake have been reported previously (Beck et al. 1983) and are shown in Figs 1 and 2 respectively. DD rats weighed significantly less than DR rats throughout the experiment. The food intake of group DR was significantly higher than that of group DD until the 19th week.

In DR and DD rats, blood glucose (Fig. 3(a)) fell significantly during the 1st week from 6.10 (SE 0.22 ) to 3.89 (SE 0.16 ) $\mathrm{mmol} / \mathrm{l}$, and then increased progressively throughout the study. There were no significant differences between the two groups until week 5 and at week 23 but levels increased more slowly in DD rats. Plasma insulin levels (Fig. 4(a)) in DR rats increased significantly throughout the experiment from $9 \cdot 0$ (SE $1 \cdot 0) \mu \mathrm{U} / \mathrm{ml}$ at week 0 to 120.4 (SE 12.7) $\mu \mathrm{U} / \mathrm{ml}$ at week 23 ; in DD rats they remained stable until week 8 and then rapidly increased; the difference between the two groups was significant $(P<0.001)$ from week 3. At weaning, plasma glucagon levels (Fig. 5(a)) were very low at $171.3(\mathrm{SE} 24.0) \mathrm{pg}$ / $\mathrm{ml}$; in DR rats they increased significantly to 335.5 (SE 20.0) $\mathrm{pg} / \mathrm{ml}$ at week 3 , and then decreased until week 23 ; in DD rats they remained significantly lower throughout the study, with a plateau between weeks 0 and 3 and a parallel evolution after week 3 . The molar ratio insulin:glucagon (I:G; calculated according to Anthony \& Faloona, 1974) showed the same variations between the two groups (Fig. 6(a)): almost stable between weeks 0 and 5 , then increasing until week 23 when levels were higher in DR groups.

The pancreatic insulin and glucagon concentrations are shown in Figs. $7(a)$ and $8(a)$ respectively. They changed in parallel in the two groups and the differences between the two 


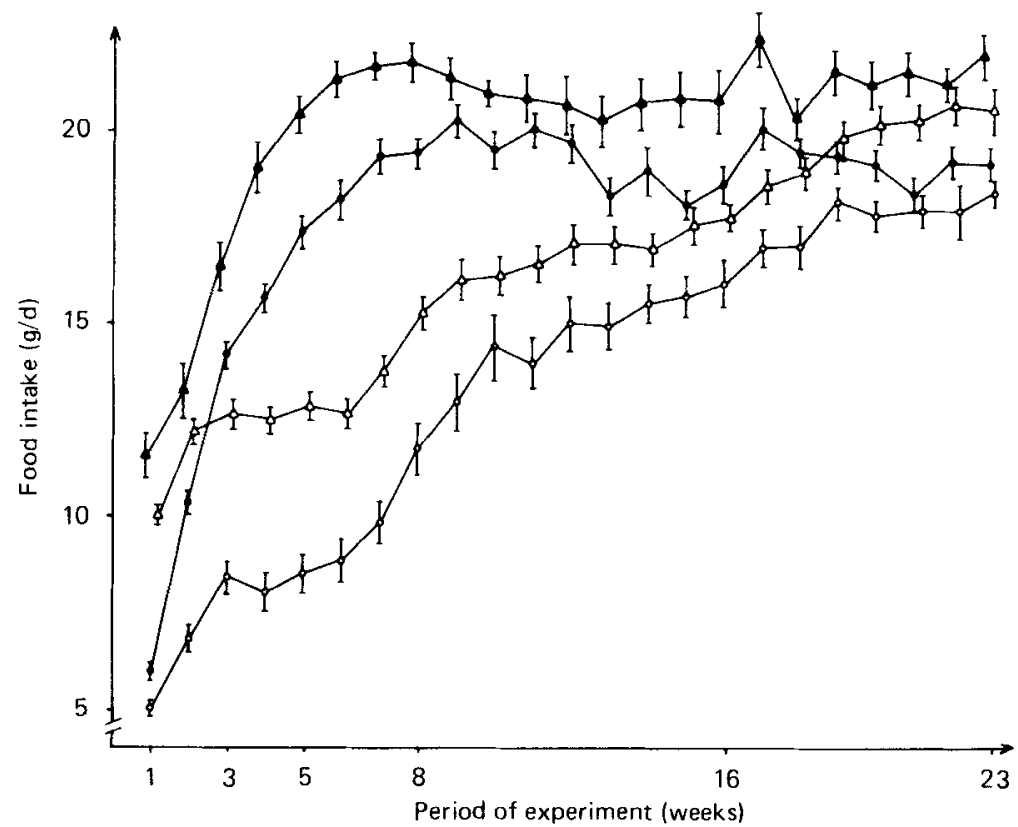

Fig. 2. Daily food intake of control and experimental rats over a period of 23 weeks after weaning: (-.-O), rats deprived before weaning, rehabilitated after weaning; $(0-0)$, rats deprived both before and after weaning; $(\boldsymbol{\Lambda}-\mathbf{\Delta})$, control rats born from normal mothers; $(\triangle \cdots \triangle)$, proteindeficient rats born from normal mothers. Points are mean values, with 1 sEM represented by vertical bars. (Figure reproduced with permission of Nutrition Research.)

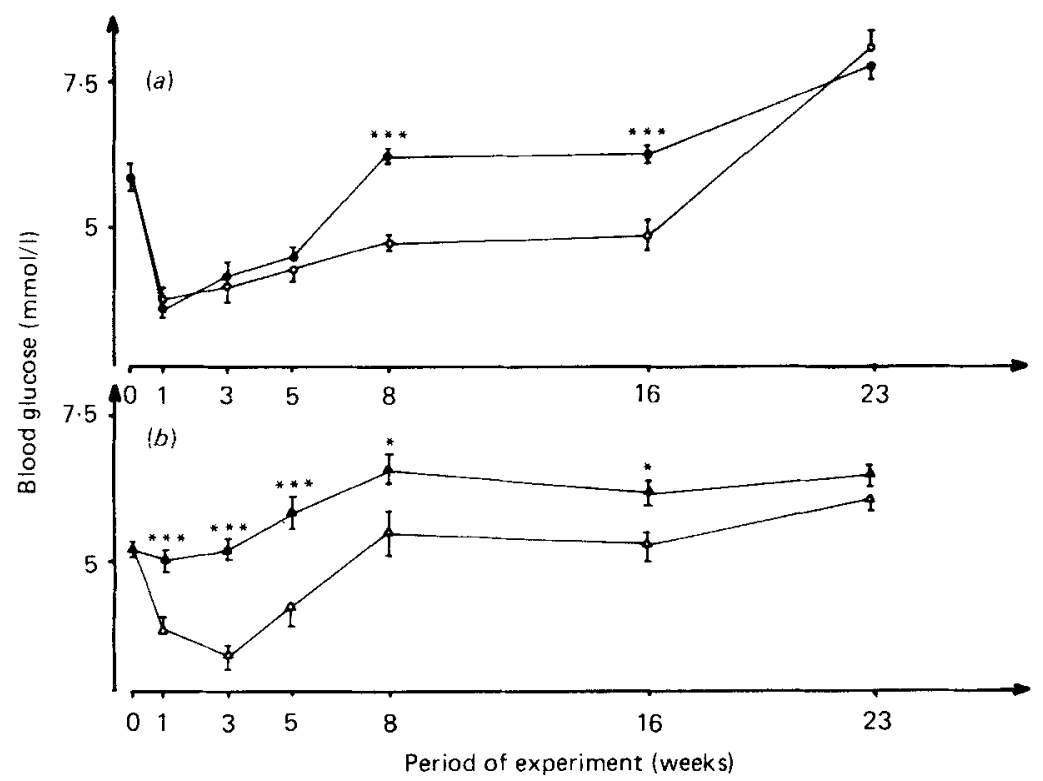

Fig. 3. Blood glucose after weaning for $(a)$, rats deprived before weaning and rehabilitated after weaning ( -1$)$ and rats deprived both before and after weaning $(\mathrm{O}-\mathrm{O}-\mathrm{O})$; and $(b)$, control rats born from normal mothers $(\Delta-\Delta)$ and protein-deficient rats born from normal mothers $(\Delta-\Delta)$. Points are mean values, with I SEM represented by vertical bars. ${ }^{*} P<0.05, * * P<0.01, * * * P<0.001$. (Fig. $3(b)$ reproduced with permission of Journal of Nutrition.) 


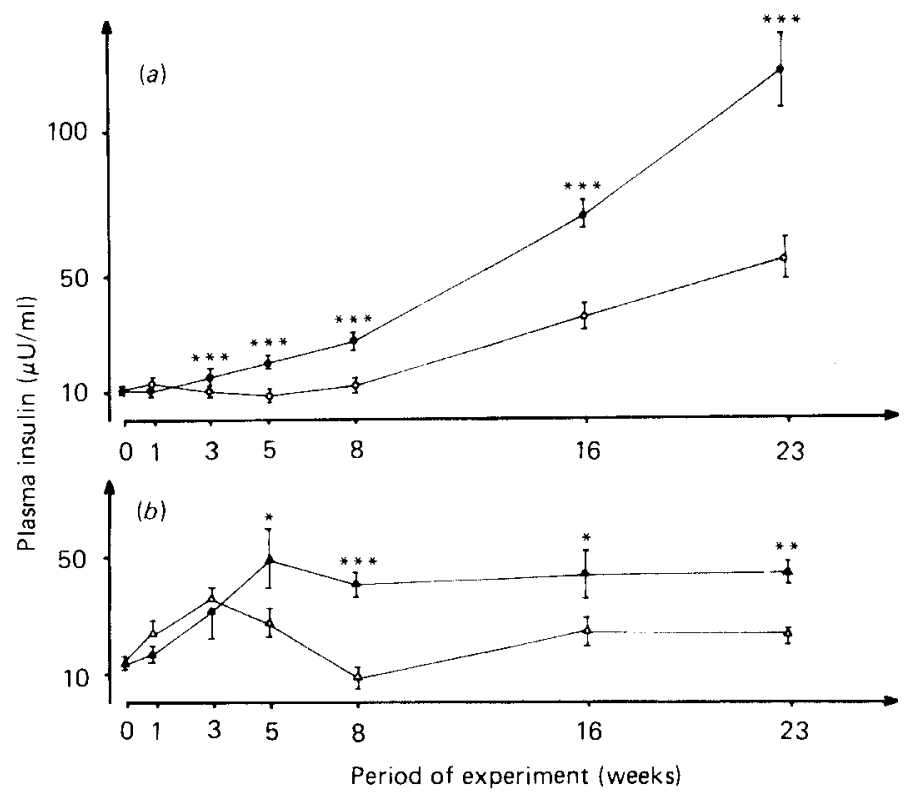

Fig. 4. Plasma insulin (IRI) after weaning for $(a)$, rats deprived before weaning and rehabilitated after weaning $(-\infty)$ ) and rats deprived both before and after weaning $(\mathrm{O}-\mathrm{O})$; and $(b)$ control rats born from normal mothers $(\mathbf{\Delta}-\mathbf{\Delta})$ and protein-deficient rats born from normal mothers $(\Delta-\Delta)$. Points are mean values, with 1 SEM represented by vertical bars. ${ }^{*} P<0.05,{ }^{* *} P<0.01,{ }^{* * *} P<0.001$. (Fig. 4(b) reproduced with permission of Journal of Nutrition.)

groups were not significant except at weeks 5,8 and 23 for pancreatic glucagon. Pancreatic insulin showed a significant drop from 210 (SE 3.6) $\mu \mathrm{g} / \mathrm{g}$ at week 0 to 68 (SE 11) at week 3; it then increased to near initial levels at week 8 and remained stable. For glucagon, the level at weaning was $9.5(\mathrm{SE} 1.1) \mu \mathrm{g} / \mathrm{g}$, it then constantly decreased in DR rats to $0.6(\mathrm{SE} 0.2) \mu \mathrm{g} / \mathrm{g}$ at week 23 ; in DD rats it showed a significant increase between weeks 16 and 23.

Table 2 shows the pancreatic hormone content:plasma hormone values for insulin and glucagon. Such a ratio for steroid hormones is inversely proportional to the excretion capacity of the adrenal glands (Parson et al. 1976). We used the same ratio for the two pancreatic hormones. These ratios decreased significantly in the two groups throughout the study indicating a high pancreatic excretion capacity. The only exception was for insulin in group DD between weeks 3 and 5 where there was a fall in the excretion capacity.

\section{DISCUSSION}

In the present experiment using rats born from malnourished mothers and either deprived or rehabilitated after weaning, we could distinguish three problems depending on the period of PEM. First the effect of PEM during pregnancy and lactation (week 0 ) on glucose homeostasis, second the influence of PEM before and after weaning (DD rats), and third the long-term effects of rehabilitation after weaning which could be studied in DR rats.

\section{Effect of PEM during pregnancy and lactation}

Malnutrition of young arising from maternal malnutrition leads to a lower body-weight at weaning. It begins during pregnancy and continues during lactation (Beck et al. 1982). During lactation there is not only energy malnutrition (Beck et al. 1982) but also nitrogen deficiency as, in a similar experiment (Crnic \& Chase, 1978), the milk $\mathrm{N}$ content of 


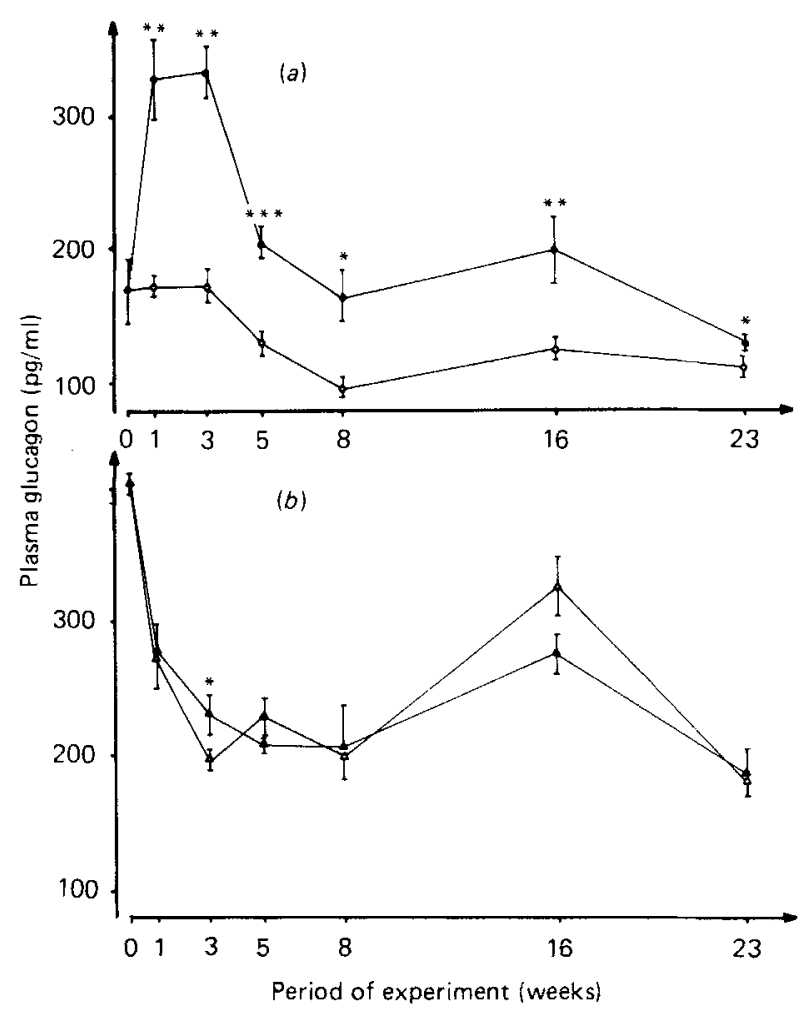

Fig. 5. Plasma glucagon (IRG) after weaning for (a), rats deprived before weaning and rehabilitated after weaning ( $-O)$ and rats deprived both before and after weaning $(\mathrm{O}-\mathrm{O})$; and $(b)$, control rats born from normal mothers ( $\mathbf{A}-\mathbf{A}$ ) and protein-deficient rats born from normal mothers $(\triangle-\triangle)$. Points are mean values, with 1 sEM represented by vertical bars. ${ }^{*} P<0.05,{ }^{* *} P<0.01$, ${ }^{* * *} P<0.001$. (Fig. $5(b)$ reproduced with permission of Journal of Nutrition.)

malnourished mothers was shown to be lower than that in mothers fed on a balanced diet.

The pancreatic insulin content was much higher in preweaning malnourished rats than in rats born from normal mothers (Fig. 7), whereas plasma insulin levels were the same (Fig. 4). The pancreatic glucagon content was also much higher in preweaning malnourished rats (Fig. 8), although in this case plasma glucagon levels were lower than normal. Preweaning insulin synthesis and secretion were therefore well protected whereas glucagon secretion seemed to be reduced. This is probably more a consequence of energy malnutrition than protein malnutrition since a similar result was described with increasing litter size of rats during lactation (Asplund, 1972). At the same time, glycaemia and the $1: G$ value were normal in comparison with normal rats. The very low value of $I: G$ is a sign of active glyconeogenesis (Unger, 1971) which is normal at weaning (Girard, 1981).

This picture was very different from that described by Heard \& Stewart (1971) since their rats had low basal blood glucose. Conversely our results were very similar to the glucose status of children in developing countries (Brasel, 1980). The normal blood glucose levels and $I: G$ value confirmed the good adaptation to malnutrition at weaning. 

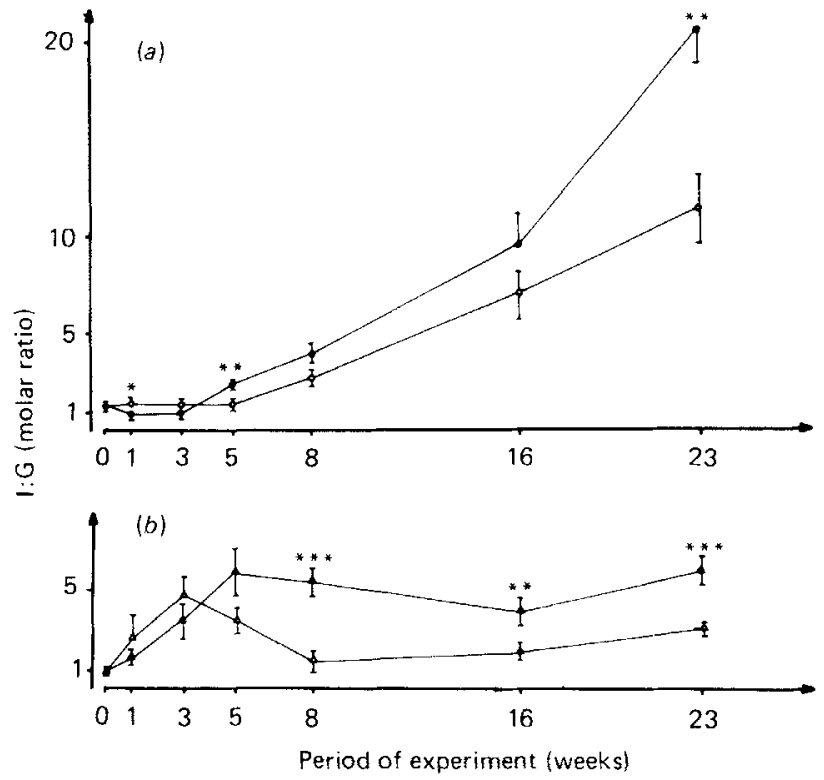

Fig. 6. Molar ratio, insulin:glucagon (I:G) after weaning for $(a)$, rats deprived before weaning and rehabilitated after weaning $(--)$ ) and rats deprived both before and after weaning $(\mathrm{O}-\mathrm{O})$; and (b), control rats born from normal mothers $(\boldsymbol{\Lambda}-\mathbf{A})$ and protein-deficient rats born from normal mothers $(\triangle-\triangle)$. Points are mean values, with 1 SEM, represented by vertical bars. ${ }^{*} P<0.05$, ${ }^{* *} P<0.01,{ }^{* * *} P<0.001$. (Fig. $6(b)$ reproduced with permission of Journal of Nutrition.)

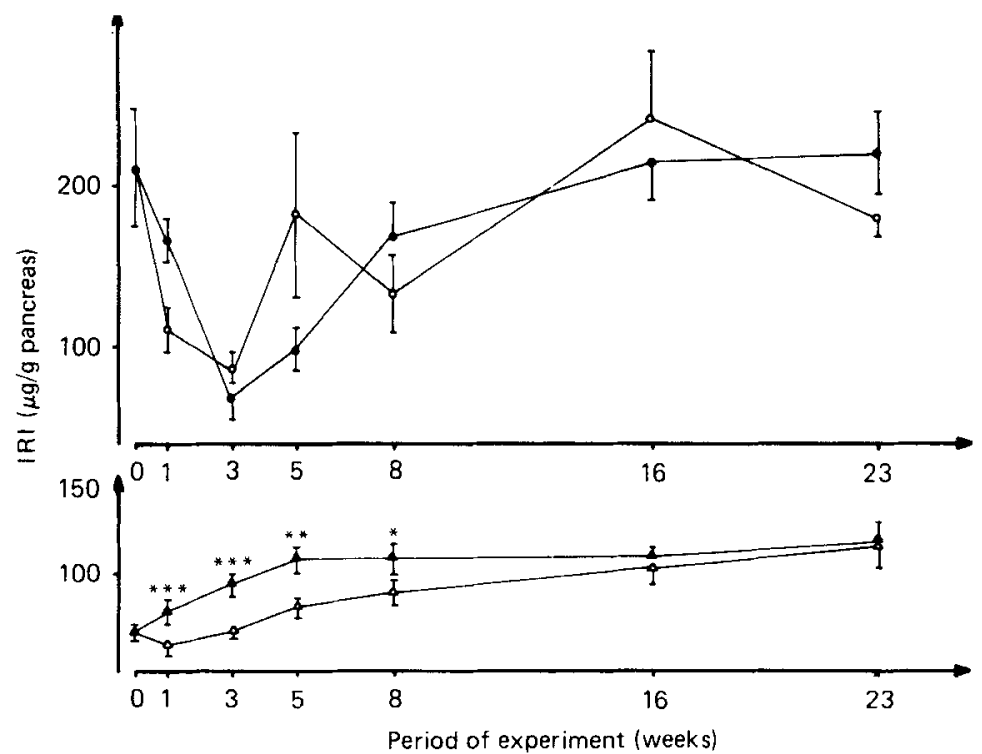

Fig. 7. Pancreatic concentration of insulin (IRI) after weaning for $(a)$, rats deprived before weaning and rehabilitated after weaning ( - - $)$ ) and rats deprived both before and after weaning $(\mathrm{O}-\mathrm{O}$ ); and $(b)$, control rats born from normal mothers $(\mathbf{A}-\mathbf{\Delta})$ and protein-deficient rats born from normal mothers $(\triangle-\triangle)$. Points are mean values, with 1 SEM represented by vertical bars. ${ }^{*} P<0 \cdot 05$, ${ }^{* *} P<0.01,{ }^{* * *} P<0.001$. (Fig. $7(b)$ reproduced with permission of Journal of Nutrition.) 


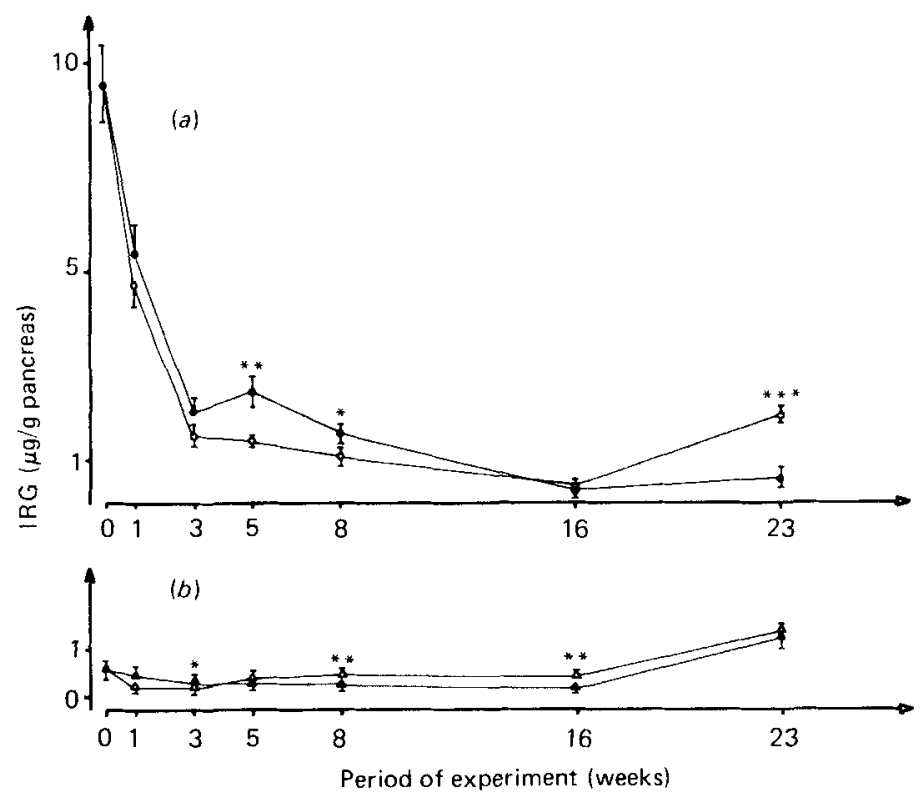

Fig. 8. Pancreatic concentration of glucagon (IRG) after weaning for (a), rats deprived before weaning and rehabilitated after weaning (-O) and rats deprived both before and after weaning $(\mathrm{O}-\mathrm{O})$; and $(b)$, control rats born from normal mothers $(\boldsymbol{\Delta}-\boldsymbol{A})$ and protein-deficient rats born from normal mothers $(\triangle-\triangle)$. Points are mean values, with 1 SEM represented by vertical bars. ${ }^{*} P<0.05,{ }^{* *} P<0.01,{ }^{* * *} P<0.001$. (Fig. $8(b)$ reproduced with permission of Journal of Nutrition.)

\section{Effect of pre-and postweaning PEM on the endocrine pancreas}

After weaning, only a few factors varied in DD rats. Despite continued protein deficiency, their pancreatic hormone contents remained at much higher levels than that in the first study (Figs. 7, 8). Between weeks 0 and 3, they decreased. The excretion capacity of their pancreas increased during the same period (Table 2). DD rats could therefore utilize their large preweaning stocks to avoid too great a fall in their plasma hormone levels. After week 3 , the insulin content decreased and then stabilized at week 8 at a level greater than the higher level in the first study (Dollet et al. 1985) (Fig. 7(b)). This is characteristic of preweaning malnutrition because the pancreatic insulin content increases with age in normally nourished rats (Lipson et al. 1981) and in protein-deficient rats born from normal mothers (Dollet et al. 1985).

The changes in the plasma factors could be divided into two periods and not into three as in the first study:

From week 1 to week 5 . Blood glucose was much lower than the weaning value and the value in control rats of the same age obtained in the first study. Nevertheless the drop between weeks 0 and 1 was lower than that for protein-deficient rats born to normal mothers (Fig. 3). The plasma insulin and $I: G$ values did not vary but they were less than those of the deficient rats in the previous study. Plasma glucagon began to fall between weeks 3 and 5 . These results were similar to those reported in studies on malnourished children (Pimstone, 1976; Robinson \& Seakins, 1982).

From week 5 to week 23 . Blood glucose levels progressively increased to reach the values obtained in protein-deficient rats during the first study, and therefore remained at lower values than normal. IRI normalized at week 23 and IRG stabilized after week 5 at low values. According to the increased $\mathrm{I}: \mathrm{G}$ value, glyconeogenesis decreased from week 5 . 


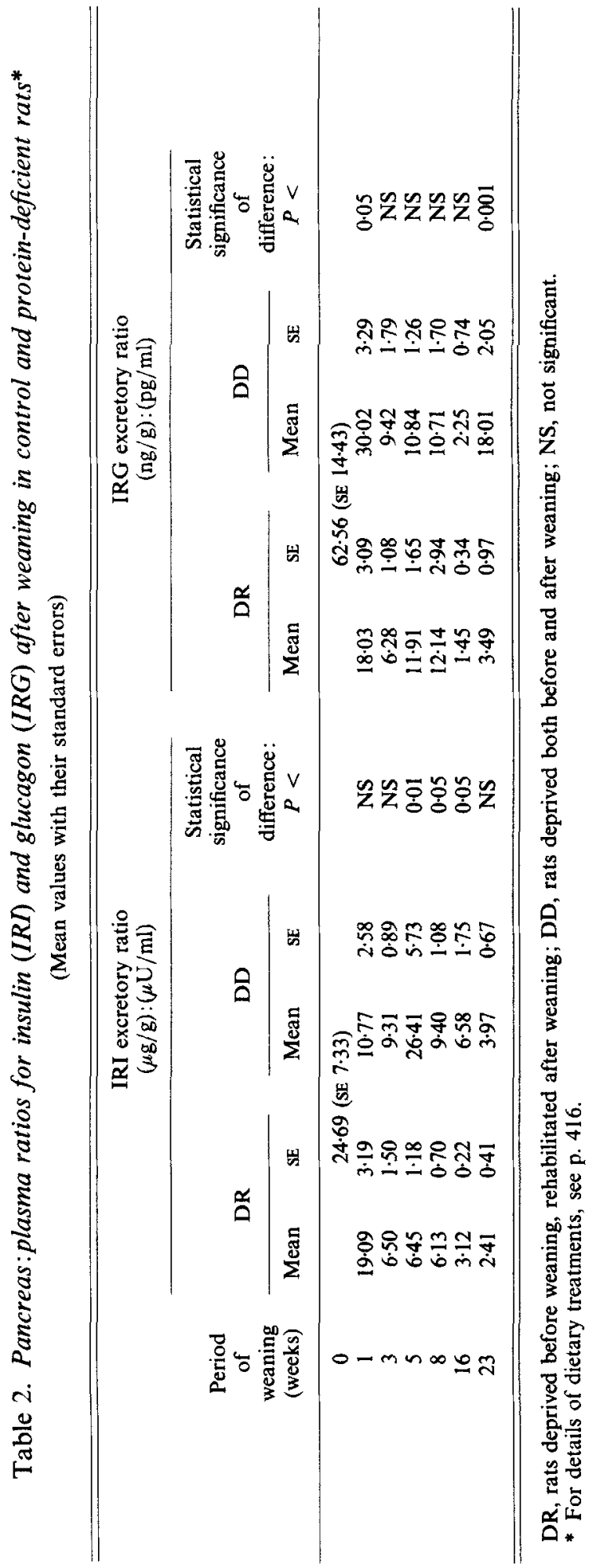


The first period (weeks 1-5) can be interpreted as a rapid adaptation to weaning. The fall in glycaemia at weaning was also present in our first study. Here it was more important than in normal rats but less than in deficient rats born from normal mothers: it is the effect of a preweaning adaptation. The lack of change in the insulin levels can be explained in the same way. As early as this period, DD rats showed the same glucose homeostasis as rats in the third period of the first study (Dollet et al. 1985) and can be considered to be already well-adapted. As during the third period of the previous study, growth is possible without great amounts of insulin; moreover it concerns here catch-up growth. The growth depends on the balance between anabolic hormones, like insulin, and catabolic hormones, like glucagon, which both remain low. Another catabolic hormone, corticosterone, might have an influence on this hormonal balance, because its plasma values are very low after preweaning malnutrition (Parson et al. 1976). In the second period (weeks 5-23), glucose homeostasis became increasingly similar to that of normal rats and growth was then possible without large glucose requirements.

Preweaning malnutrition in rats did not worsen either glucose homeostasis or insulin secretion. On the contrary, it improved adaptation to postweaning malnutrition: there was no tendency to misadaptation as in the second period of our first study and no worsening of the growth delay. The endocrine pancreas is known to present its hyperplasic phase after weaning (Jolicoeur et al. 1980). The present study is a further demonstration that only organs with hyperplasia before birth are damaged by preweaning malnutrition (Zamenhof \& Van Marthens, 1982). It is probably also an explanation of the good adaptation of the exocrine pancreas in our rats (Sarles et al. 1987).

\section{Effect of rehabilitation at weaning on the pancreas}

The pancreatic insulin content fell during the first 3 weeks in DR rats: intense excretion (Table 2) took place and the stocks reached the same values as in the control rats of the first study (Fig. 7). For glucagon, the large increase between weeks 0 and 3 brought the plasma values to identical levels as in normal rats at weaning; after week 3, plasma glucagon fell to the normal value for rats of the same age (Fig. 8). These rates of variation of the insulin and glucagon levels were exactly the same as those in children on a recovery diet after PEM (Robinson \& Seakins, 1982). The rapid normalization of IRG and low increase in blood glucose and IRI indicate that glycoregulation does not take priority.

The most interesting finding in these rats was their long-term development: they presented an insulin resistance since they became hyperglycaemic and hyperinsulinic from week 16. Similar characteristics of glucose homeostasis are observed in obese subjects (Kolterman et al. 1986). Ravelli et al. (1976) have described a high prevalence of obesity in adult humans born from malnourished mothers; similar results were obtained in rats malnourished during the first 2 weeks of pregnancy (Jones \& Friedman, 1982). In our experiment, DR rats were not obese, probably because of the longer period of malnutrition (throughout pregnancy and lactation). Nevertheless they presented a similar glucose status to obesity as mice malnourished during lactation (Aubert et al. 1980). It is probably necessary to continue the experiment for longer in order to see this effect of rehabilitation after preweaning malnutrition.

\section{CONCLUSION}

Pre- and postweaning malnourished rats are a better model of PEM seen in developing countries than rats only malnourished after weaning. If parental malnutrition during pregnancy and lactation improves pancreatic adaptation to postweaning malnutrition, it also predisposes offspring rehabilitated at weaning to insulin resistance. However in 
humans some organs and, in particular, the brain, are definitely abnormal even after rehabilitation (Bedi et al. 1982). It is therefore obligatory to take into account not only the children, but also their parents in order to eliminate all the effects of malnutrition.

\section{REFERENCES}

Anthony, L. E. \& Faloona, G. R. (1974). Metabolism 23, 303-306.

Asplund, K. (1972), Diabetologia 8, 153-159.

Aubert, R., Suquet, J. P. \& Lemonnier, D. (1980). Journal of Nutrition 110, 649-661.

Beck, B., Dollet, J. M., Max, J. P. \& Debry, G. (1982). Reproduction, Nutrition, Développement 22, 841-849.

Beck, B., Dollet, J. M., Max, J. P. \& Debry, G. (1983). Nutrition Research 3, 743-748.

Bedi, K. S., Birzgalis, H. R., Mahon, M., Smart, J. L. \& Wareham, A. C. (1982). British Journal of Nutrition 47, 417-431.

Brasel, J. A. (1980). Pediatric Research 14, 1299 1303.

Coward, W. A., Paul, A. A. \& Prentice, A. M. (1984). Federation Proceedings 43, 2432-2437.

Crnic, L. S. \& Chase, H. P. (1978). Journal of Nutrition 108, 1755-1760.

Dollet, J. M., Beck, B., Villaume, C. Max, J. P. \& Debry, G. (1985). Journal of Nutrition 115, $1581-1588$.

Gabr, M. (1981). World Review of Nutrition and Dietetics 36, 9099.

Girard, J. R. (1981). Ciba Foundation Symposium 86, 234-250.

Heard, C. R. C. \& Stewart, R. J. C. (1971). Hormones 2, 40-64.

James, W. P. \& Coore, H. G. (1970). American Journal of Clinical Nutrition 23, 386-389.

Jolicoeur, L., Asselin, J. \& Morisset, J. (1980). Biochemical Research 1, 482-488.

Jones, A. J. \& Friedman, M. I. (1982). Science 215, 1518-1519.

Kolterman, O. G., Insel, J., Saekow, M. \& Olefsky, J. (1986). Journal of Clinical Investigation 65, 1272-1284.

Lipson, L. G., Bobrycki, V. A., Bush, M. J., Tietjen, G. E. \& Yoon, A. (1981). Endocrinology 102, $620-624$.

Milner, R. D. (1971). Pediatric Research 5, 33-39.

Parson, P. L., Shrader, R. E. \& Zeman, F. J. (1976). Journal of Nutrition 106, 392-404.

Pimstone, B. L. (1976). Clinical Endocrinology 5, 7995.

Ravelli, G. P., Stein, Z. A. \& Susser, R. W. (1976). New England Journal of Medicine 295, 349-353.

Rengers, S. D. \& Zeman, F. J. (1983). Nutrition Reports International 27, 463-473.

Robinson, H. M. \& Seakins, A. (1982). Pediatric Research 16, 1011-1015.

Sarles, H., Lahaie, R., Dollet, J. M., Beck, B., Michel, R. \& Debry, G. (1987). Digestive Disease and Sciences 32, $520-528$.

Tafari, N., Naeye, R. L. \& Gobezie, A. (1980). British Journal of Obstetrics and Gynaecology 87, $222-226$.

Unger, R. H. (1971). Diabetes 20, 834-838.

Weinkove, C., Weinkove, E. A. \& Pimstone, B. L. (1976). Clinical Science and Molecular Medicine 50, $153-163$.

Zamenhof, S. \& Van Marthens, E. (1982). Journal of Nutrition 112, 972-977. 